\title{
Obtaining mathematical functions of the propeller thrust and torque coefficients fluctuations at non-uniform wake flow including geometry effects
}

\author{
Kumars Mahmoodi, Hassan Ghassemi*, and Hashem Nowruzi \\ Department of Maritime Engineering, Amirkabir University of Technology, Hafez Ave, No 424, 15875-4413 Tehran, Iran
}

Received: 20 July 2017 / Accepted: 1 March 2018

\begin{abstract}
The main purpose of this paper is to obtain mathematical functions of the propeller thrust and torque coefficients fluctuations at non-uniform flow. Two types of inflow wakes from Seiun-Maru ship and INSEAN 7000 DWT Tanker are investigated for the B-series propeller. The computed results include the thrust and torque coefficients fluctuations and their mathematical functions under the influence of two different wakes for one blade and all blades of the studied propellers. To this accomplishment, variation of thrusts and torques coefficients under different pitch ratio, expanded area ratio and number of blades are investigated using classical mathematical methods in one cycle and the Fourier coefficients with ten terms are presented for each case. The results of thrust and torque coefficients at different propeller geometries are presented and discussed.
\end{abstract}

Keywords: B-series propeller / non-uniform wake / thrust and torque fluctuations / geometry effects

\section{Introduction}

Non-uniform wakes at the ship stern are significantly impressive on the hydrodynamic performance and structural characteristics of the marine propellers. On one hand, these wakes cause to fluctuating loads on the propulsive system. On the other hand, non-uniform inflows wake regime which is depended on the shape of the ship hull is impressive on the hydrodynamic efficiency of propellers. Consequently, estimation of propeller hydrodynamic performance under non-uniform wake is a necessity step to design of efficient propellers.

Until now, several experimental tests and numerical studied are conducted to study of ship hull wakes by researchers [1-12]. In this regards, pressure distribution, open water characteristics and thrust fluctuation of conventional and highly skewed propellers under nonuniform wakes are studied numerically by Ghassemi [5]. Ji et al. [6] investigated the cavitating flow around a submerged propeller under a non-uniform wake, numerically. They also studied the excited pressure fluctuation around the propellers operating in a non-uniform wake and shown that the major source of the pressure fluctuations is the acceleration generated by the changes of the cavity volume [7]. Effects of wake scale on the pressure fluctuations factors is studied with a simulation procedure

\footnotetext{
* e-mail: gasemi@aut.ac.ir
}

suggested by Berger et al. [8]. Greco et al. [9] conducted a numerical study to investigate of propeller thrust and torque, slipstream velocities, blade pressure distribution and pressure disturbance on marine propeller under free wake in an open water condition. Shin et al. [10] studied the unsteady cavitation on a tip-modified propeller under two types of ship wakes including model test measurement and bare hull RNAS simulations. Moreover, Martin et al. [11] studied maneuverability of submarines by considering the propeller forces and moments under the hull wake with coupled CFD/potential flow propeller solver. Similar works on the subject were also presented in Broglia et al. [12]. In order to investigate of unsteady forces on marine propellers under the non-uniform and non-stationary wake, Abbas et al. [13] conducted a numerical simulation by using hybrid URANS-LES model.

Recently, pressure distributions, limiting-streamlines and cavitation volumes of the E779A propeller in open water and in a cavitation tunnel behind wake generating plates is reported numerically by Vaz et al. [14]. They used eight different flow codes and CFD software for their study. Pereira et al. [15] conducted an experimental test to study the cavitating propeller operating in a non-uniform wake. They suggested quantitative correlations between the near pressure fields and the cavitation pattern. Moreover, in an experimental study, Ueno and Tsukada [16] estimated the fluctuating full-scale propeller torque and thrust under free-running model ship condition in waves and under nonuniform wakes. Sun et al. [17] calculated the propeller 


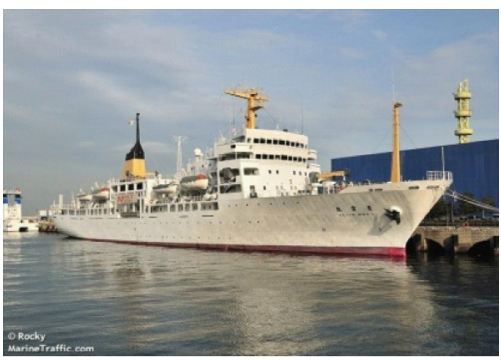

(A)

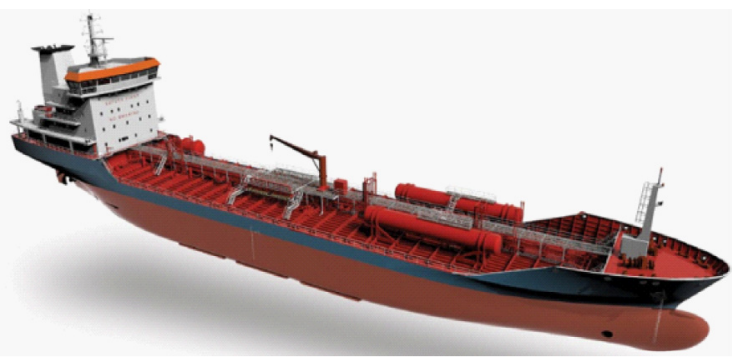

(B)

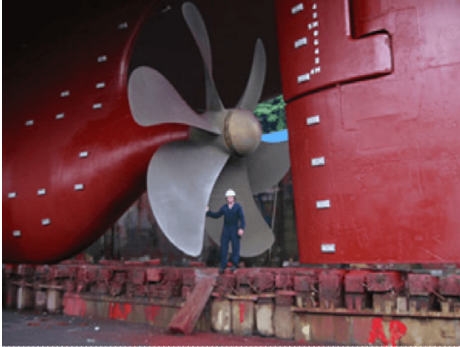

(C)

Fig. 1. (A) Seiun-Maru training ship, (B) INSEAN 7000 DWT Tanker, (C) propeller behind the ship.

exciting force under the non-uniform wake of KCS ship in oblique flow by using hybrid method of RANS and volume of fluid model. Also, hydro-elastic analysis on marine propeller under the inflow wakes and the effects of shafts is studied numerically by Zou et al. [18].

For this purpose, the velocities from non-uniform wakes of Seiun-Maru ship (measured by Ukon et al. $[19,20]$ ) and INSEAN 7000 DWT Tanker (measured by Salvatore et al. [21,22]) are implemented. Figure 1 shows our considered two types of the real ship and propeller behind the ship. Then, variation of thrusts and torques coefficients under different number of blades, pitch ratio, and expanded area ratio (i.e. fifteen different propeller cases with 3-7 blades, pitch ratio and expanded area ratio varied from 0.2 to 1.4 and 0.2 to 1.1 , respectively) are studied by using classical mathematical methods in one cycle and their Fourier coefficients with ten terms are presented.

During recent years, Ghassemi et al. worked on the different propulsor (poded propeller, ducted propeller, surface propeller and propeller with augmentation devices) numerical analysis by BEM and CFD [23-25], ship hullpropeller interaction [26], calculations of the sound pressure level of the marine propeller in low frequency [27], hydrodynamic characteristics of the ducted propeller and its different geometries effect [28] as well as the propeller efficiency enhancement of the blade's tip reformation [29]. Based on cited works, mathematical functions of the nonuniform wake flow entered to the propeller geometries is not well known. Therefore, in the current study, thrust and torque of the propeller with different geometries are evaluated. A numerical code is prepared to read the input data like wake flow behind the ship and propeller geometries, then calculate the propeller thrust and torque fluctuations against one cycle rotation. Present study employed on two different wake flows (by two ships) and the results are presented and discussed.

The rest of this paper is organized as follows: Section 2 gives an outline of the mathematical formulation techniques to compute unsteady thrust, torque and hydrodynamics coefficients. Section 3 provides some details about non-uniform wake flow. Section 5 presents the results of computations of the thrust and torque fluctuations with different propeller geometries and the results are presented and discussed. This is followed by the conclusion remarks in Section 5.

\section{Mathematical formulations}

In this section a short overview of formulas utilized to calculate of propeller thrust and torque coefficients for one blade and all blades are presented.

The axial and tangential components of the inflow wake velocity into the propeller disc typically vary around the circumference at a given radius $r$. Let $V_{a}$ and $V_{t}$ are the axial and tangential velocities, respectively, and $\theta$ the angle measured from the vertical upward. It can be represented the non-uniform wake velocity field including tangential and axial components via the Fourier series as follows:

$$
\left\{\begin{array}{l}
V_{a}(r, \theta)=\sum_{m=0}^{\infty}\left\{a_{m}(r) \cos (m \theta)+b_{m}(r) \sin (m \theta)\right\} \\
V_{t}(r, \theta)=\sum_{m=0}^{\infty}\left\{a^{\prime}(r) \cos (m \theta)+b^{\prime}(r) \sin (m \theta)\right\}
\end{array},\right.
$$

where $a_{m}, a^{\prime}$, and $b_{m}, b^{\prime}$ are Fourier coefficients. In practice, only a limited set of harmonic components are used. In this paper $m=10$ is considered for all the computations.

Also, $n(r, \theta)$ is the instantaneous revolution rate at the angle $\theta$ :

$$
n(r, \theta)=n-\frac{V_{t}(r, \theta)}{X \pi R}
$$

where $n, R=(D / 2)$, and $X=(r / R)$ are rotational speed $(\mathrm{RPM})$, radious of propeller, and non-dimentional radial section, respectively. The advance coefficient for a blade at the angle $\theta$ is:

$$
J(r, \theta)=\frac{V_{a}(r, \theta)}{n(r, \theta) D} .
$$

In the non-uniform wake flow, the thrsut and torque coefficients of the propeller are obtained using polynomial regression analysis as given below:

$\left\{\begin{array}{l}K_{T}(r, \theta)=\sum_{n, S_{n}, t_{n}, u_{n}, v_{n}} C_{n}(J(r, \theta))^{S_{n}}(P / D)^{t_{n}}(\mathrm{EAR})^{u_{n}}(Z)^{v_{n}} \\ K_{Q}(r, \theta)=\sum_{n, S_{n}, t_{n}, u_{n}, v_{n},} C_{n}(J(r, \theta))^{S_{n}}\left(\frac{P}{D}\right)^{t_{n}}(\mathrm{EAR})^{u_{n}}(Z)^{v_{n}}\end{array}\right.$, 


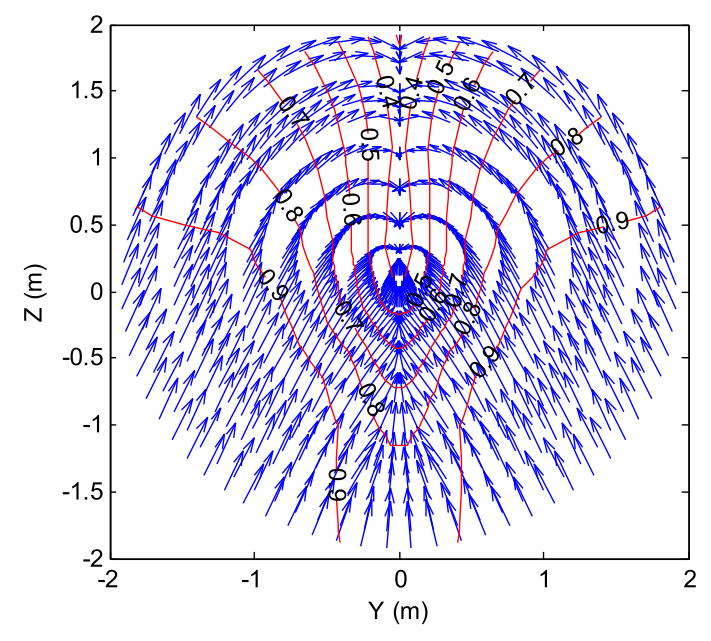

(a) Seiun-Maru ship

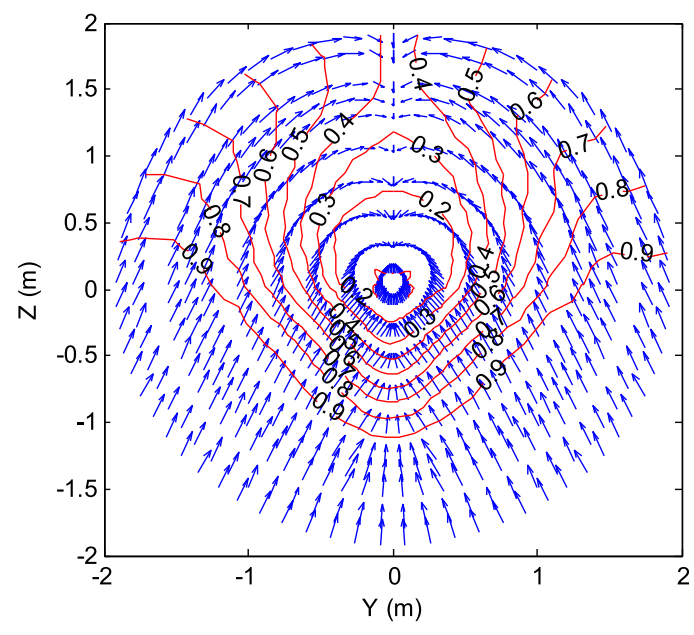

(b) 7000 DWT Tanker

Fig. 2. Contour and vector wake velocity distribution.

where the $Z$, EAR and $P / D$ are number of blade, expanded are ratio and pitch ratio, respectively. The values of $n, S_{n}$, $t_{n}, u_{n}$ and $v_{n}$ are regression coefficients [30,31].

These thrust and torque coefficients can be defined by Fourier transformation as follows:

$$
\left\{\begin{array}{c}
K_{T}(r, \theta)=\sum_{m=0}^{\infty}\left\{c_{m}(r) \cos (m \theta)+d_{m}(r) \sin (m \theta)\right\} \\
K_{Q}(r, \theta)=\sum_{m=0}^{\infty}\left\{c^{\prime}(r) \cos (m \theta)+d^{\prime}(r) \sin (m \theta)\right\}
\end{array}\right.
$$

where $c_{m}, c^{\prime}, d_{m}$, and $d^{\prime}$ are Fourier coefficients for thrust and torque coefficients.

Then, $K_{T}(\theta)$ and $K_{Q}(\theta)$ are calculated as follows:

$$
\left\{\begin{array}{l}
K_{T}(\theta)=\frac{\int_{r_{h}}^{R} K_{T}(r, \theta) r d r}{\int_{r_{h}}^{R} r d r} \\
K_{Q}(\theta)=\frac{\int_{r_{h}}^{R} K_{Q}(r, \theta) r d r}{\int_{r_{h}}^{R} r d r}
\end{array}\right.
$$

Using Simpson's rule, the integrals may be determined by following formula:

$$
\left\{\begin{array}{c}
K_{T}(\theta)=\frac{\sum_{i=0}^{L} C_{S_{i}} K_{T_{i}}(r, \theta) r_{i}}{\sum_{i=0}^{L} C_{S_{i}} r_{i}} \\
K_{Q}(\theta)=\frac{\sum_{i=0}^{L} C_{S_{i}} K_{Q}(r, \theta) r_{i}}{\sum_{i=0}^{L} C_{S_{i}} r_{i}}
\end{array}\right.
$$

where $L$ and $C_{S_{i}}$ are number of ordinate and Simpson's multiplier, respectively.

The main goal of this paper is to find thrust and torque coefficients $\left(K_{T}(\theta)\right.$ and $\left.K_{Q}(\theta)\right)$ variations during one angular position $(\theta=0 \sim 360)$ at different propeller geometries under non-uniform wake flows.

\section{Non-uniform wake flow}

The nominal inflow wake data of the studied propellers were obtained in two cases: (1) full-scale condition at the stern of the Seiun-Maru ship hull, which was carried out by Ukon et al. $[19,20]$ at the National Maritime Research Center (NMRC), in Japan, and (2) the nom-uniform wake measurements of the INSEAN 7000 DWT Tanker measured by Salvatore et al. [21,22]. INSEAN 7000 DWT Tanker is the name of a model ship design developed by CNRINSEAN for the purpose of hydrodynamic studies on ship propulsion. The INSEAN 7000 DTW Tanker is a single-screw, bulbous bow ship designed for cruise speed at 14 knots. Velocimetry measurements to determine the hull nominal wake were performed at the large CTO towing tank by using a 5 -hole Pitot-tube technique.

Non-uniform wake measurements of Seiun-Maru ship and INSEAN 7000 DTW tanker are done in ten radial sections. Contour and vector wake velocity distribution at propeller plane are presented in Figure 2. The measured wake flow contours indicate the axial speed of water and the arrows denote the transverse velocity field in front of the propeller in the full scale. Figure 3 shows the axial and tangential velocity component of wake flow in fractions of the ship speed at different radial sections in the propeller plane. Also, Table 1 shows Fourier coefficients of axial and tangential velocity distribution in fractions of the ship speed in the propeller plane at $X=r / R=0.7$ based on equation (1). The Discrete Fourier Transform (DFT) interpolation of these velocities is presented in Figure 4.

\section{Results and discussions}

\subsection{B-series propellers with different geometries}

Two wakes of the ships (namely Seiun-Maru and Insean Tanker) are selected to obtaing the propeller thrust and toruqe. Table 2 is given the main dimensions of those ships and their employed propeller. Figure 5 shows some examples of the studied propellers. In this study, instead 

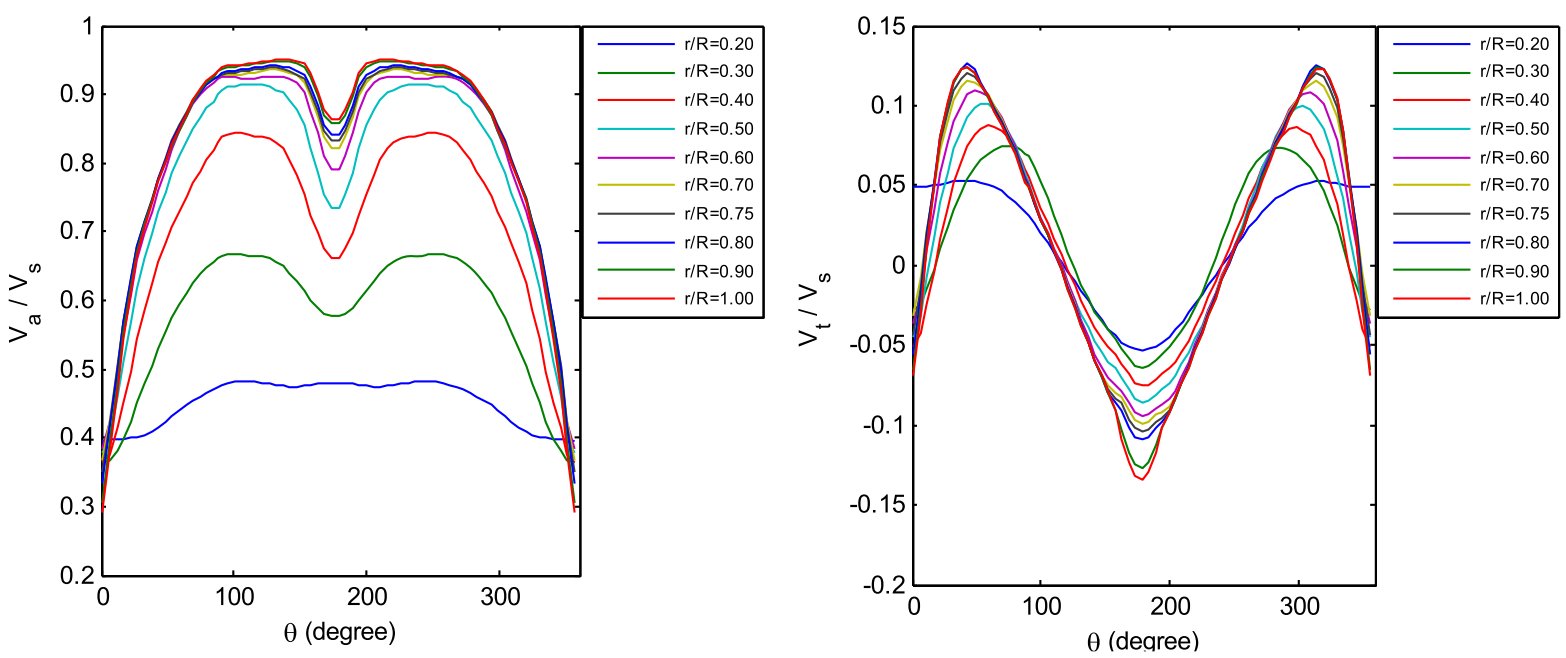

(a) Seiun-Maru ship
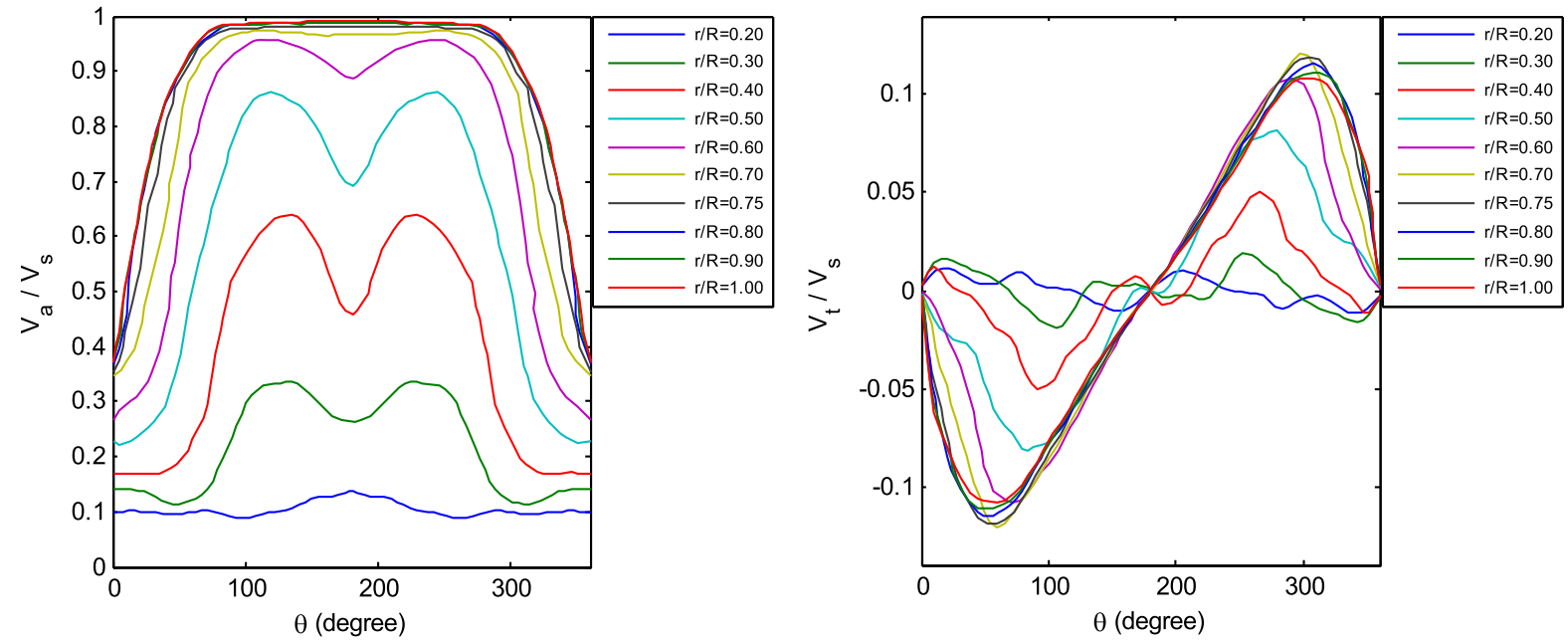

(b) 7000 DWT Tanker

Fig. 3. Axial (left) and tangential (right) velocity distribution in the propeller plane at different radial sections.

Table 1. Fourier coefficients of axial and tangential velocity distribution at $r / R=0.7$.

\begin{tabular}{|c|c|c|c|c|c|c|c|c|}
\hline \multirow{3}{*}{$m$} & \multicolumn{4}{|c|}{ Seiun-Maru ship } & \multicolumn{4}{|c|}{7000 DWT Tanker } \\
\hline & \multicolumn{2}{|c|}{ Axial velocity } & \multicolumn{2}{|c|}{ Tangential velocity } & \multicolumn{2}{|c|}{ Axial velocity } & \multicolumn{2}{|c|}{ Tangential velocity } \\
\hline & $a_{m}$ & $b_{m}$ & $a_{m}^{\prime}$ & $b_{m}^{\prime}$ & $a_{m}$ & $b_{m}$ & $a_{m}^{\prime}$ & $b_{m}^{\prime}$ \\
\hline 0 & 0.824627 & 0 & 0.018679 & 0 & 0.78715 & 0 & $-3.9 \mathrm{E}-05$ & 0 \\
\hline 1 & -0.15370 & 0.006903 & 0.079933 & 0.00219 & -0.28172 & 0.003133 & -0.00264 & -0.10427 \\
\hline 2 & -0.13067 & 0.011761 & -0.04738 & -0.00029 & -0.12152 & 0.002721 & -0.00118 & -0.02012 \\
\hline 3 & -0.04588 & 0.006215 & -0.02383 & 0.003655 & -0.0171 & 0.000583 & 0.000259 & 0.0049 \\
\hline 4 & -0.04640 & 0.008421 & -0.02087 & 0.003587 & -0.00282 & 0.000124 & -0.00011 & 0.001881 \\
\hline 5 & -0.00932 & 0.002127 & -0.01288 & 0.00307 & -0.00825 & 0.000455 & -0.0003 & -0.0004 \\
\hline 6 & -0.02602 & 0.007181 & -0.00677 & 0.000754 & -0.00558 & 0.000349 & -0.00036 & -0.00239 \\
\hline 7 & -0.00765 & 0.002485 & -0.0053 & 0.002038 & -0.00217 & 0.000142 & -0.0004 & -0.0009 \\
\hline 8 & -0.01392 & 0.005223 & -0.00378 & 0.001507 & -0.00012 & $6.95 \mathrm{E}-05$ & -0.00018 & 0.000206 \\
\hline 9 & -0.00394 & 0.001685 & -0.00198 & 0.000927 & -0.00069 & $3.74 \mathrm{E}-05$ & 0.00019 & 0.001009 \\
\hline
\end{tabular}



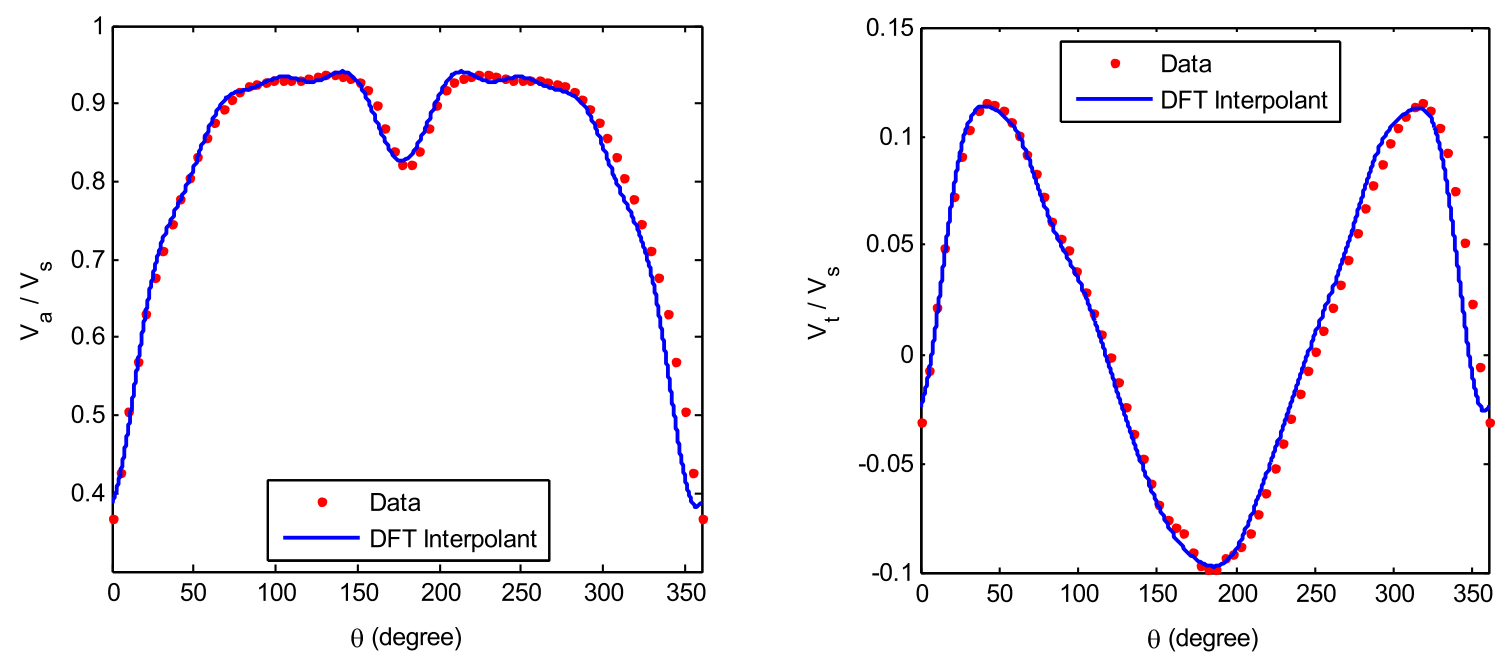

(a) Seiun-Maru ship
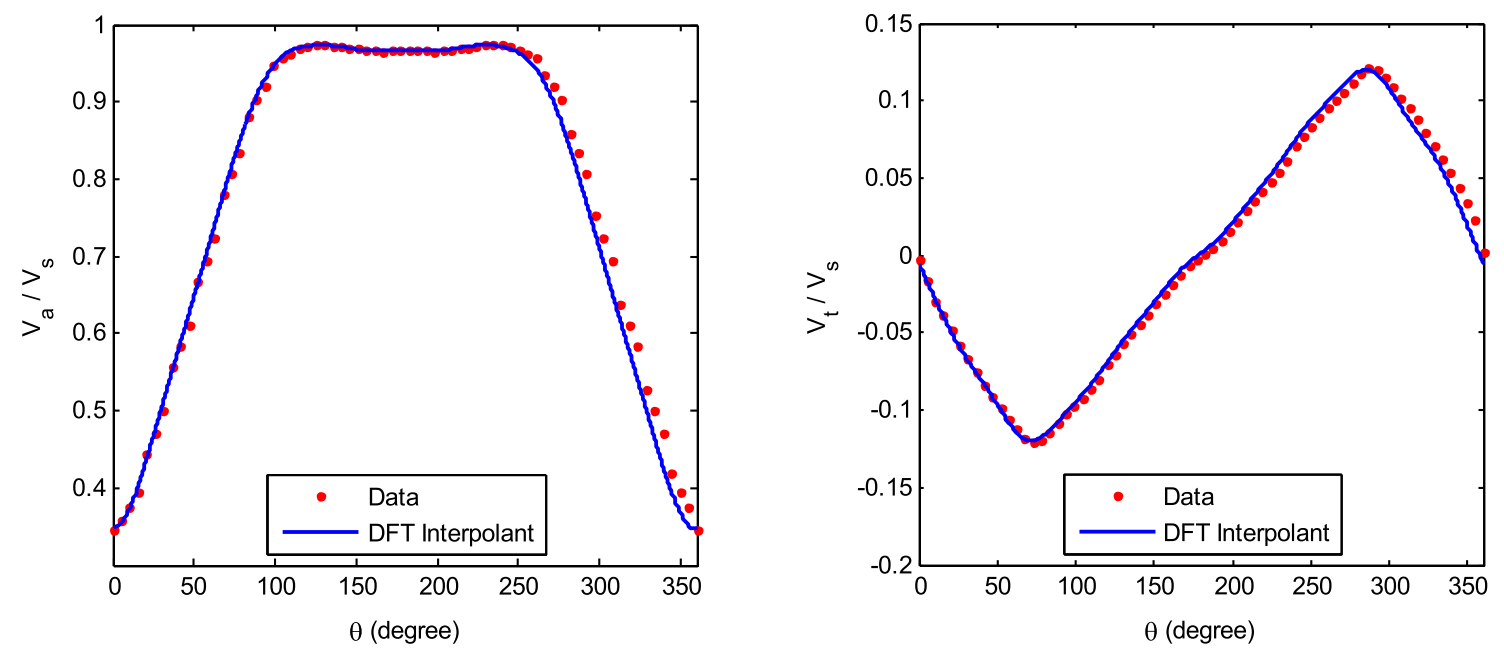

(b) 7000 DWT Tanker

Fig. 4. DFT interpolation of axial and tangential velocity distribution at $r / R=0.7$.

of the original employed propeller, we used different Bseries propeller in order to obtain thrust and torque coefficients variations and Fourier mathemtical formulas under non-uniform operating conditions.

Seiun-Maru training ship has design speed 17.5 knots with propeller diameter $3.6 \mathrm{~m}$ while INSEAN tanker has 14 knots with propeller diameter $3.85 \mathrm{~m}$. Propeller rotating speed is selected $120 \mathrm{RPM}$. To obtain an understanding of the effect of various propeller geometries parameters upon thrust and torque coefficient, variations of these parameters with $Z, P / D$ and EAR are investigated. Also, the Fourier coefficients with ten terms based on equation (5) of the B-series propeller are presented. All instantaneous revolution rate, advance ratio, thrust and torque coefficients are calculated through equations $(2-4)$.

\subsection{Thrust and torque coefficients}

Figure 6 shows one blade thrust and torque coefficients fluctuations under Seiun-Maru wake. Generally, thrust and torque coefficients are bigger at some angular positions and smaller at some others. The small humps appearing in the both $K_{T}$ and $K_{Q}$ plots may be caused by tangential inflow components, which show pronounced jump at angular position equal to $180^{\circ}$. Also, Figure 7 presents total thrust and torque coefficient fluctuations of mentioned propellers with different number of blades. Generally, it can be concluded from Figure 7 that the thrust and torque coefficients increases with increasing the number of blades. Also, generally it can be said that the fluctuations of thrust and torque coefficients decrease with increasing the number of blades under the same operating conditions. 
Table 2. Main dimensions of the ships and their employed propeller.

\begin{tabular}{lll}
\hline Ship type & Seiun-Maru (Training ship) & INSEAN (Tanker) \\
\hline Parameter & & \\
Overall length [m] & 116 & - \\
Length between perpendicular [m] & 105 & 94.0 \\
Breadth [m] & 17.90 & 15.4 \\
Draft [m] & 6.3 & 6.0 \\
Displacement [ton] & 5781.3 & 6820 \\
Design speed [kt] & 11 & 14 \\
Propeller diameter [m] & 3.6 & 3.85 \\
Number of blade (Z) & 5 & 4 \\
Expanded area ration (EAR) & 0.65 & 0.58 \\
Pitch ratio (P/D) & 0.95 & 1.0 \\
Rake angle [deg] & 6 & 3 \\
Skew angle [deg] & 10.5 & 13 \\
\hline
\end{tabular}
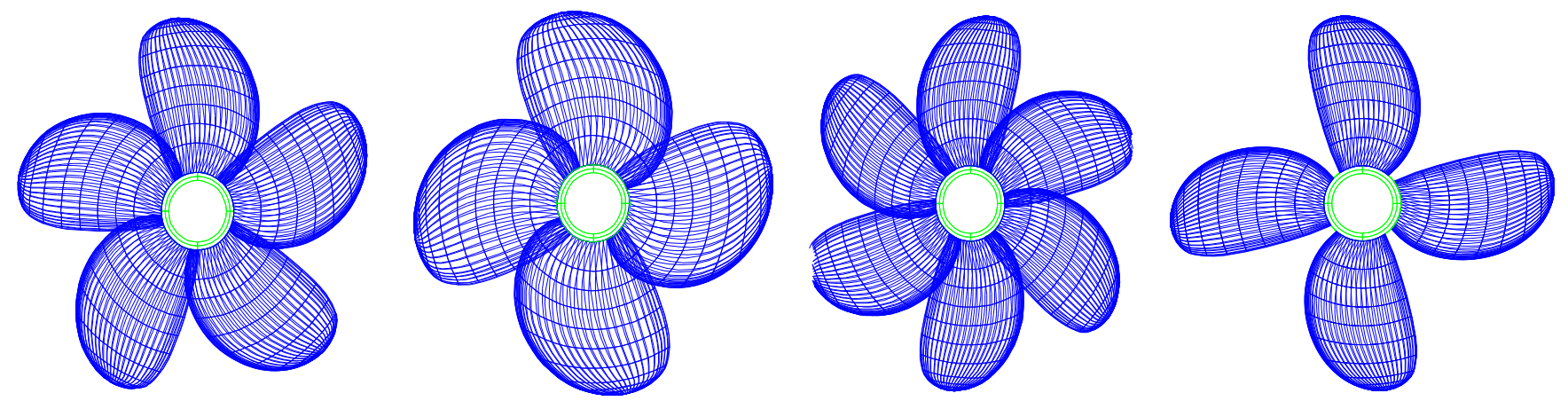

Fig. 5. Examples of the different B-series propellers.
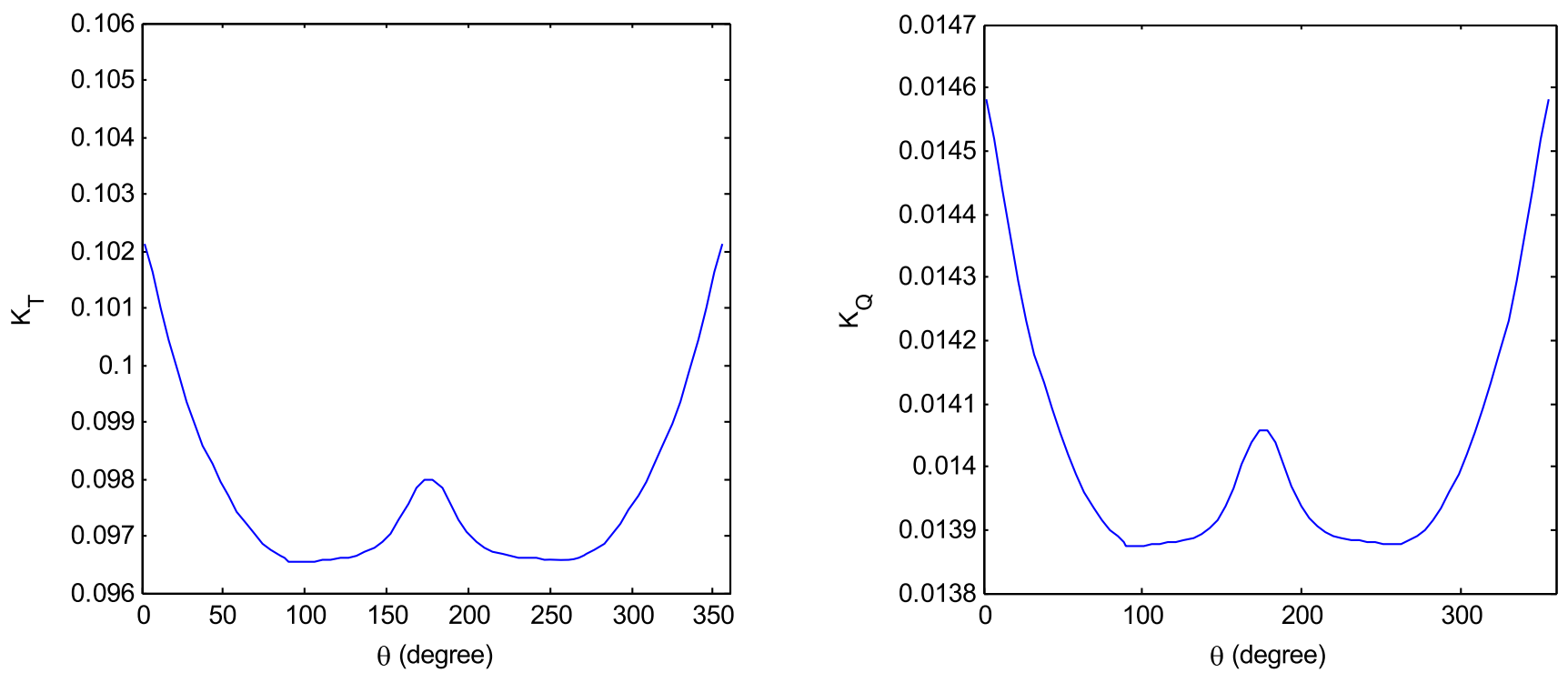

Fig. 6. One blade thrust and torque coefficients fluctuations under influence of Seiun-Maru ship wake $(Z=3, \mathrm{EAR}=0.55, P /$ $D=0.95$ ). 

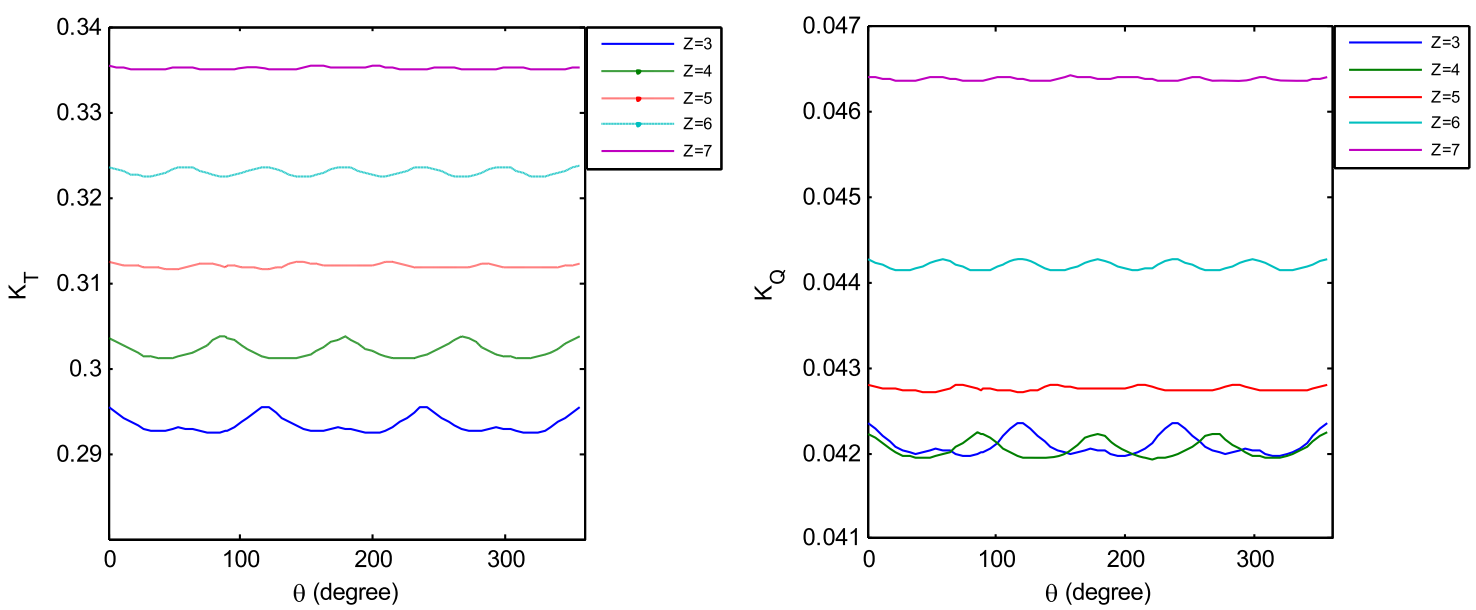

(a) Seiun-Maru ship
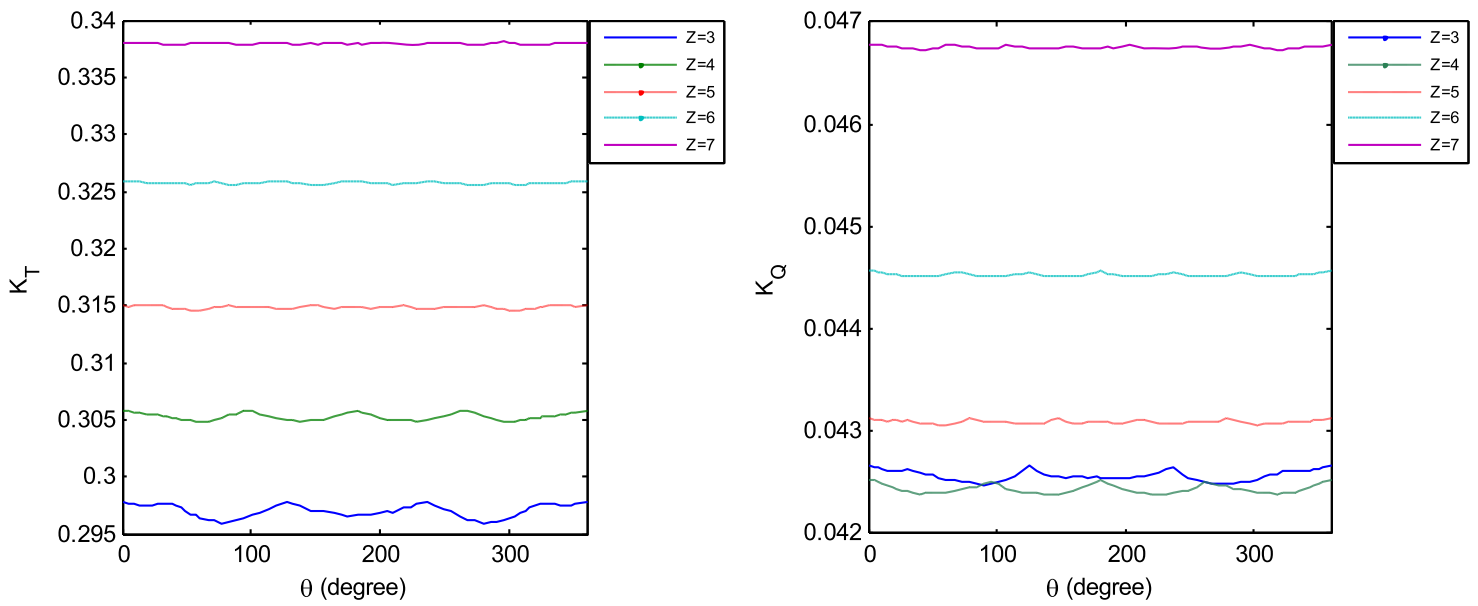

(b) 7000 DWT Tanker

Fig. 7. Total thrust and torque coefficients fluctuations at different blade numbers $(\mathrm{EAR}=0.55, P / D=0.95)$.

Table 3. Fourier coefficients of the the thrust and torque $(Z=5, P / D=0.95$, EAR $=0.55)$.

\begin{tabular}{|c|c|c|c|c|c|c|c|c|}
\hline \multirow{3}{*}{$m$} & \multicolumn{4}{|c|}{ Seiun-Maru ship } & \multicolumn{4}{|c|}{7000 DWT Tanker } \\
\hline & \multicolumn{2}{|c|}{ Thrust coefficient $\left(K_{T}\right)$} & \multicolumn{2}{|c|}{ Torque coefficient $\left(K_{Q}\right)$} & \multicolumn{2}{|c|}{ Thrust coefficient $\left(K_{T}\right)$} & \multicolumn{2}{|c|}{ Torque coefficient $\left(K_{Q}\right)$} \\
\hline & $c_{m}$ & $d_{m}$ & $c_{m}^{\prime}$ & $d_{m}^{\prime}$ & $c_{m}$ & $d_{m}$ & $c_{m}^{\prime}$ & $d_{m}^{\prime}$ \\
\hline 0 & $-5.44 \mathrm{E}-05$ & $-3.73 \mathrm{E}-06$ & $-5.99 \mathrm{E}-06$ & $-4.23 \mathrm{E}-07$ & $3.88 \mathrm{E}-05$ & $4.46 \mathrm{E}-07$ & $6.45 \mathrm{E}-06$ & $-6.89 \mathrm{E}-08$ \\
\hline 1 & $7.19 \mathrm{E}-05$ & $-7.94 \mathrm{E}-07$ & $7.96 \mathrm{E}-06$ & $-6.23 \mathrm{E}-08$ & $9.79 \mathrm{E}-05$ & $-4.26 \mathrm{E}-06$ & $7.42 \mathrm{E}-06$ & $1.84 \mathrm{E}-07$ \\
\hline 2 & $-3.26 \mathrm{E}-05$ & $-1.62 \mathrm{E}-06$ & $-3.69 \mathrm{E}-06$ & $-1.61 \mathrm{E}-07$ & 8.17E-05 & $8.04 \mathrm{E}-07$ & $8.18 \mathrm{E}-06$ & $-3.75 \mathrm{E}-07$ \\
\hline 3 & $7.03 \mathrm{E}-05$ & $-2.02 \mathrm{E}-05$ & $7.82 \mathrm{E}-06$ & $-2.33 \mathrm{E}-06$ & $1.56 \mathrm{E}-05$ & $-6.28 \mathrm{E}-06$ & $7.23 \mathrm{E}-06$ & $-4.35 \mathrm{E}-07$ \\
\hline 4 & $2.07 \mathrm{E}-04$ & $3.02 \mathrm{E}-05$ & $2.45 \mathrm{E}-05$ & $3.06 \mathrm{E}-06$ & $-6.85 \mathrm{E}-05$ & $1.09 \mathrm{E}-05$ & $-1.59 \mathrm{E}-06$ & $5.33 \mathrm{E}-08$ \\
\hline 5 & $-3.62 \mathrm{E}-05$ & $-8.52 \mathrm{E}-06$ & $-4.08 \mathrm{E}-06$ & $-1.09 \mathrm{E}-06$ & $-7.21 \mathrm{E}-05$ & $1.22 \mathrm{E}-06$ & $-9.79 \mathrm{E}-06$ & $1.11 \mathrm{E}-06$ \\
\hline 6 & $2.39 \mathrm{E}-05$ & $1.99 \mathrm{E}-05$ & $2.77 \mathrm{E}-06$ & $2.20 \mathrm{E}-06$ & $3.44 \mathrm{E}-05$ & $-5.47 \mathrm{E}-06$ & $6.43 \mathrm{E}-06$ & $-1.52 \mathrm{E}-06$ \\
\hline 7 & $-3.53 \mathrm{E}-05$ & $1.42 \mathrm{E}-05$ & $-3.97 \mathrm{E}-06$ & $1.62 \mathrm{E}-06$ & $-4.07 \mathrm{E}-06$ & $9.84 \mathrm{E}-07$ & 4.49E-06 & $-9.95 \mathrm{E}-07$ \\
\hline 8 & $-3.09 \mathrm{E}-07$ & $-1.66 \mathrm{E}-05$ & $4.81 \mathrm{E}-09$ & $-1.89 \mathrm{E}-06$ & $-1.05 \mathrm{E}-05$ & $3.69 \mathrm{E}-06$ & $9.73 \mathrm{E}-07$ & $-4.44 \mathrm{E}-08$ \\
\hline 9 & $1.22 \mathrm{E}-04$ & $-4.80 \mathrm{E}-05$ & $1.38 \mathrm{E}-05$ & $-5.42 \mathrm{E}-06$ & $-1.80 \mathrm{E}-06$ & $-1.42 \mathrm{E}-06$ & $6.63 \mathrm{E}-07$ & $-3.26 \mathrm{E}-07$ \\
\hline
\end{tabular}



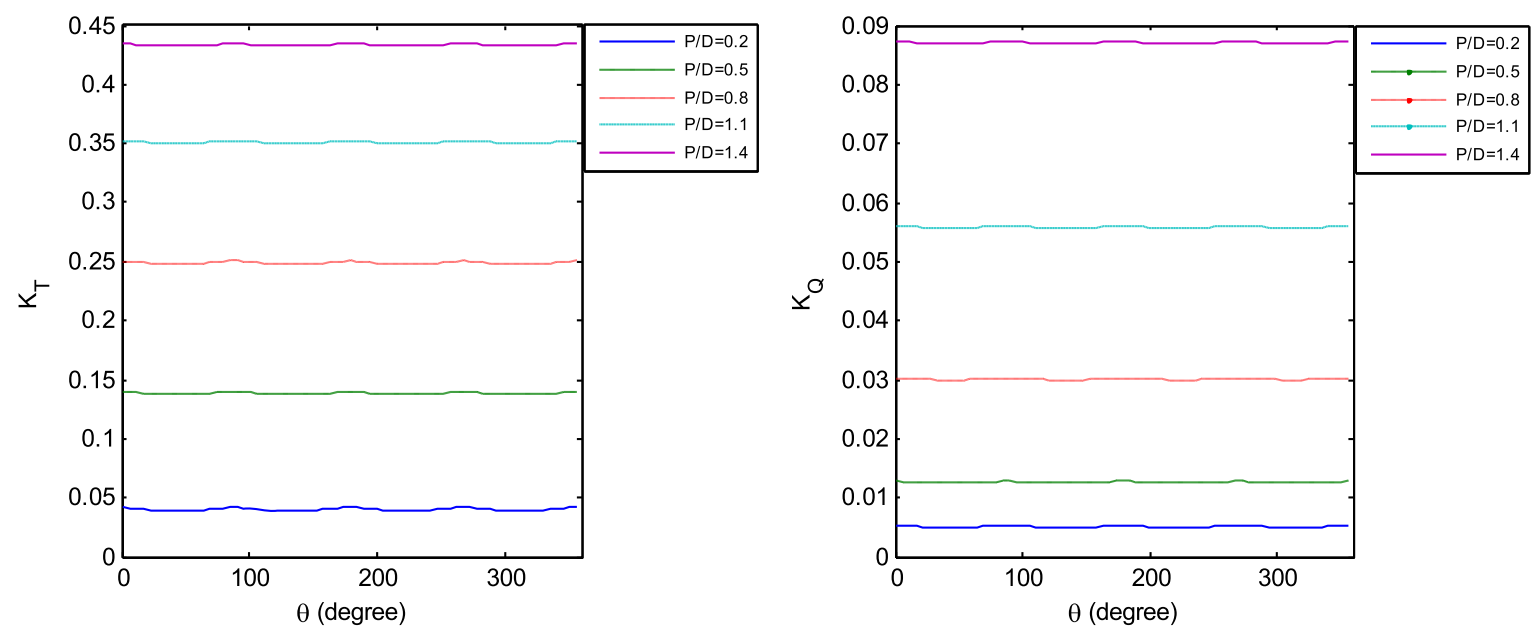

(a) Seiun-Maru ship
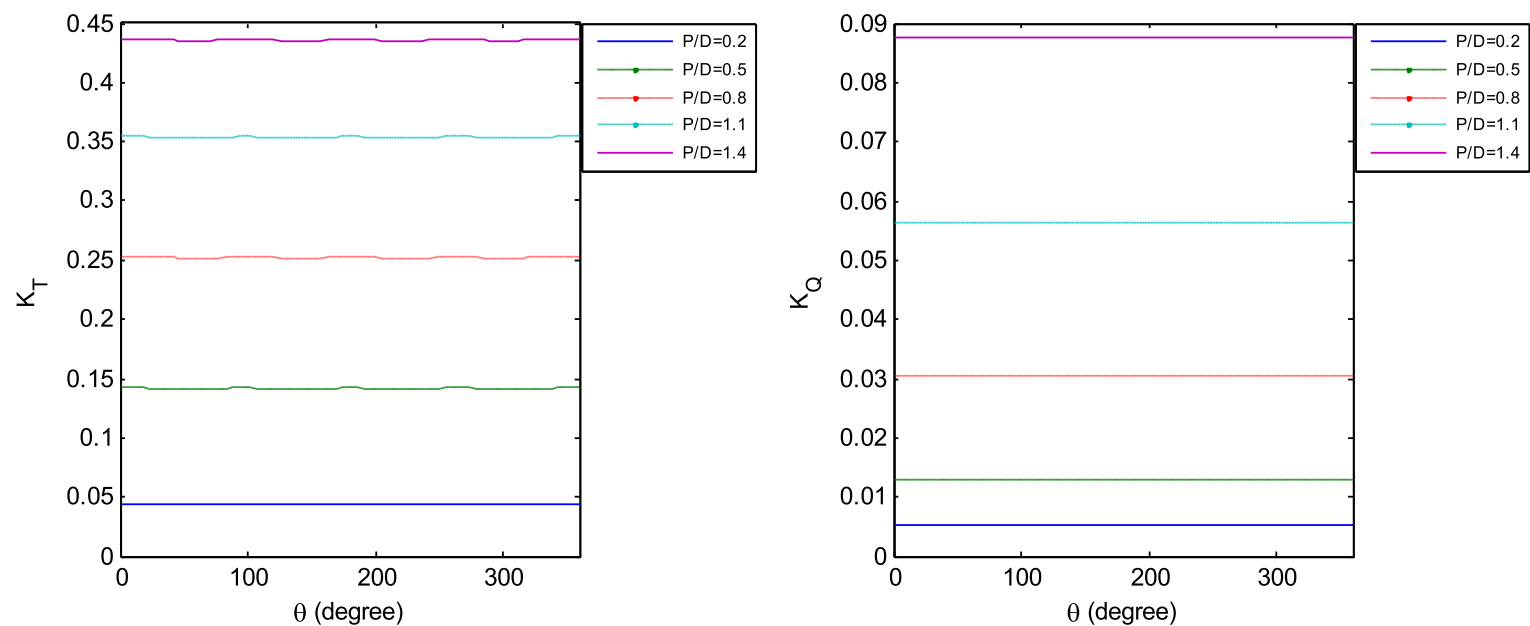

(b) 7000 DWT Tanker

Fig. 8. Total thrust and torque coefficients fluctuations at different pitch ratio $(Z=4, \mathrm{EAR}=0.55)$.
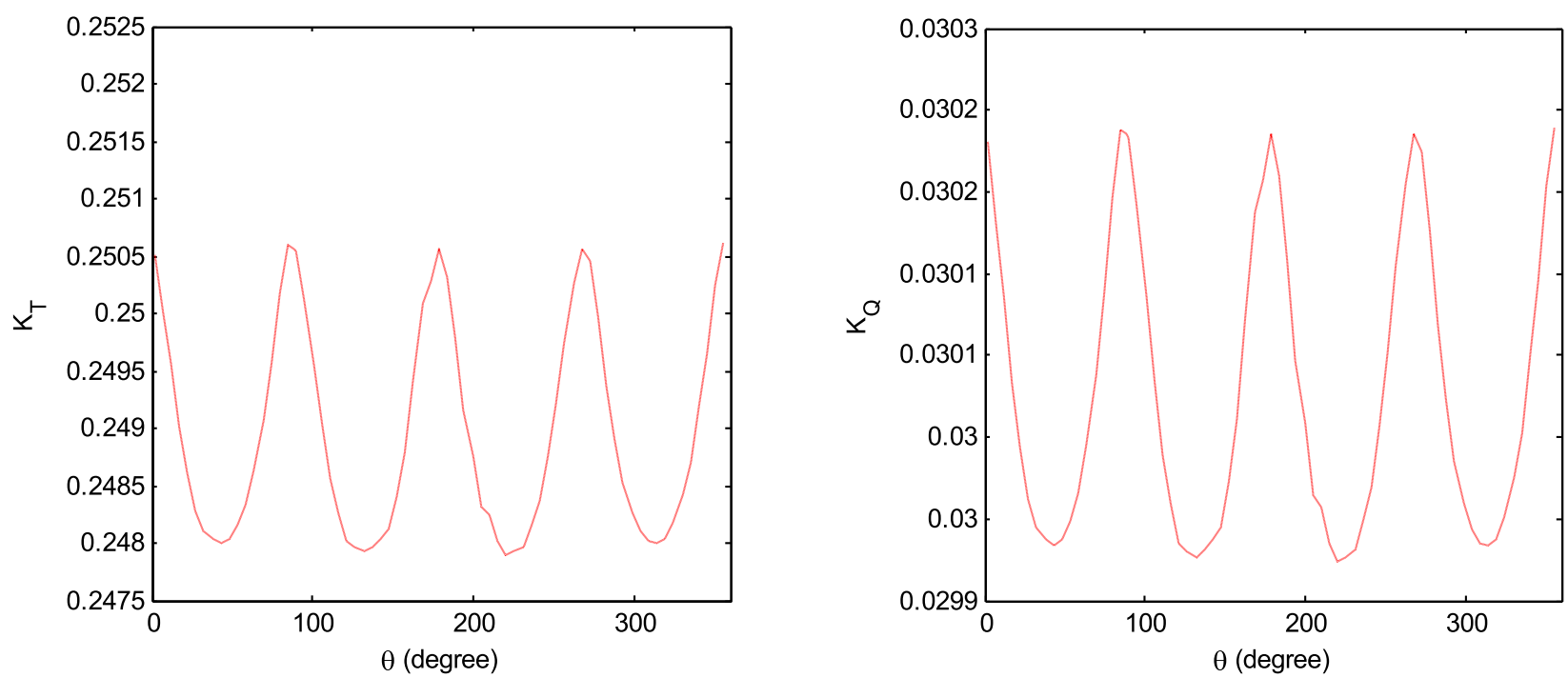

Fig. 9. Total thrust and torque coefficients fluctuations at different pitch ratio $(\mathrm{EAR}=0.55, Z=4, P / D=0.8)$. 
Table 4. Fourier coefficients of the thrust and torque $(Z=4, P / D=0.80, \mathrm{EAR}=0.55)$.

\begin{tabular}{|c|c|c|c|c|c|c|c|c|}
\hline \multirow{3}{*}{$m$} & \multicolumn{4}{|c|}{ Seiun-Maru ship } & \multicolumn{4}{|c|}{7000 DWT Tanker } \\
\hline & \multicolumn{2}{|c|}{ Thrust coefficient $\left(K_{T}\right)$} & \multicolumn{2}{|c|}{ Torque coefficient $\left(K_{Q}\right)$} & \multicolumn{2}{|c|}{ Thrust coefficient $\left(K_{T}\right)$} & \multicolumn{2}{|c|}{ Torque coefficient $\left(K_{Q}\right)$} \\
\hline & $c_{m}$ & $d_{m}$ & $c_{m}^{\prime}$ & $d_{m}^{\prime}$ & $c_{m}$ & $d_{m}$ & $c_{m}^{\prime}$ & $d_{m}^{\prime}$ \\
\hline 0 & $4.96 \mathrm{E}-05$ & $4.43 \mathrm{E}-05$ & $4.85 \mathrm{E}-06$ & $4.36 \mathrm{E}-06$ & $1.00 \mathrm{E}-04$ & $8.40 \mathrm{E}-07$ & $1.01 \mathrm{E}-05$ & $-1.33 \mathrm{E}-07$ \\
\hline 1 & $-5.51 \mathrm{E}-05$ & $1.27 \mathrm{E}-05$ & $-5.41 \mathrm{E}-06$ & $1.24 \mathrm{E}-06$ & $1.70 \mathrm{E}-04$ & $3.05 \mathrm{E}-06$ & $1.46 \mathrm{E}-05$ & $1.30 \mathrm{E}-07$ \\
\hline 2 & $-4.33 \mathrm{E}-05$ & $-9.45 \mathrm{E}-05$ & $-4.23 \mathrm{E}-06$ & $-9.27 \mathrm{E}-06$ & $1.96 \mathrm{E}-04$ & $-5.25 \mathrm{E}-06$ & $1.67 \mathrm{E}-05$ & $-6.87 \mathrm{E}-07$ \\
\hline 3 & 0.001247 & -0.00019 & 0.000122 & $-1.81 \mathrm{E}-05$ & $1.49 \mathrm{E}-04$ & $-9.23 \mathrm{E}-06$ & 4.13E-05 & $-2.55 \mathrm{E}-06$ \\
\hline 4 & $3.94 \mathrm{E}-06$ & $-5.15 \mathrm{E}-05$ & $4.21 \mathrm{E}-07$ & $-5.04 \mathrm{E}-06$ & $-2.60 \mathrm{E}-04$ & $1.45 \mathrm{E}-05$ & $-1.78 \mathrm{E}-05$ & $1.24 \mathrm{E}-06$ \\
\hline 5 & $7.29 \mathrm{E}-06$ & $1.82 \mathrm{E}-06$ & 7.06E-07 & $1.77 \mathrm{E}-07$ & $1.59 \mathrm{E}-04$ & $-2.84 \mathrm{E}-06$ & $7.30 \mathrm{E}-06$ & $-5.86 \mathrm{E}-07$ \\
\hline 6 & $-1.98 \mathrm{E}-05$ & $-1.56 \mathrm{E}-05$ & $-1.96 \mathrm{E}-06$ & $-1.54 \mathrm{E}-06$ & $4.32 \mathrm{E}-05$ & $-6.56 \mathrm{E}-06$ & 4.83E-06 & $-6.75 \mathrm{E}-07$ \\
\hline 7 & 0.000268 & $-8.33 \mathrm{E}-05$ & $2.64 \mathrm{E}-05$ & $-8.17 \mathrm{E}-06$ & $-1.14 \mathrm{E}-05$ & $-3.83 \mathrm{E}-06$ & $4.22 \mathrm{E}-06$ & $-5.06 \mathrm{E}-07$ \\
\hline 8 & $-9.47 \mathrm{E}-06$ & $-2.65 \mathrm{E}-05$ & $-9.02 \mathrm{E}-07$ & $-2.61 \mathrm{E}-06$ & $-2.93 \mathrm{E}-05$ & $1.03 \mathrm{E}-05$ & $-5.91 \mathrm{E}-06$ & $8.28 \mathrm{E}-07$ \\
\hline 9 & $1.54 \mathrm{E}-05$ & $-1.45 \mathrm{E}-05$ & $1.50 \mathrm{E}-06$ & $-1.42 \mathrm{E}-06$ & $7.01 \mathrm{E}-05$ & $-9.53 \mathrm{E}-06$ & $6.18 \mathrm{E}-06$ & $-1.37 \mathrm{E}-06$ \\
\hline
\end{tabular}
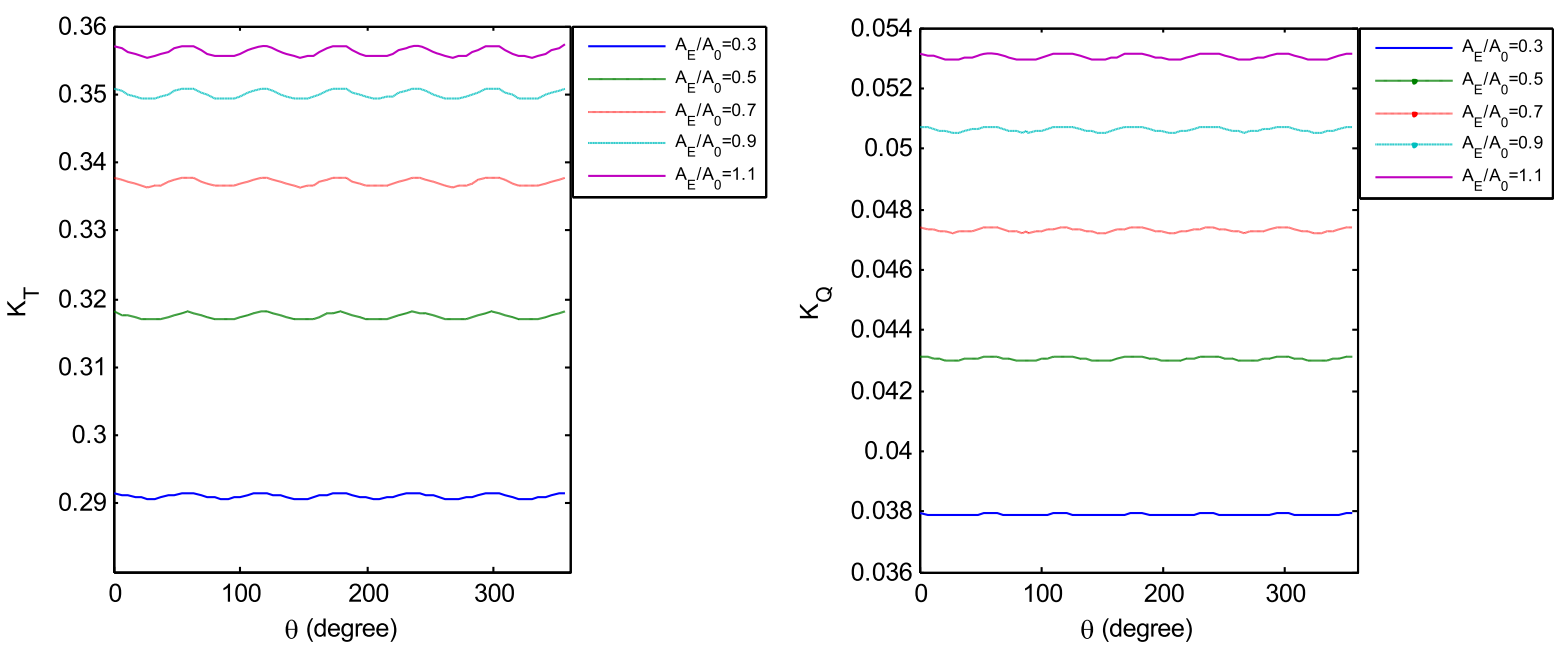

(a) Seiun-Maru ship
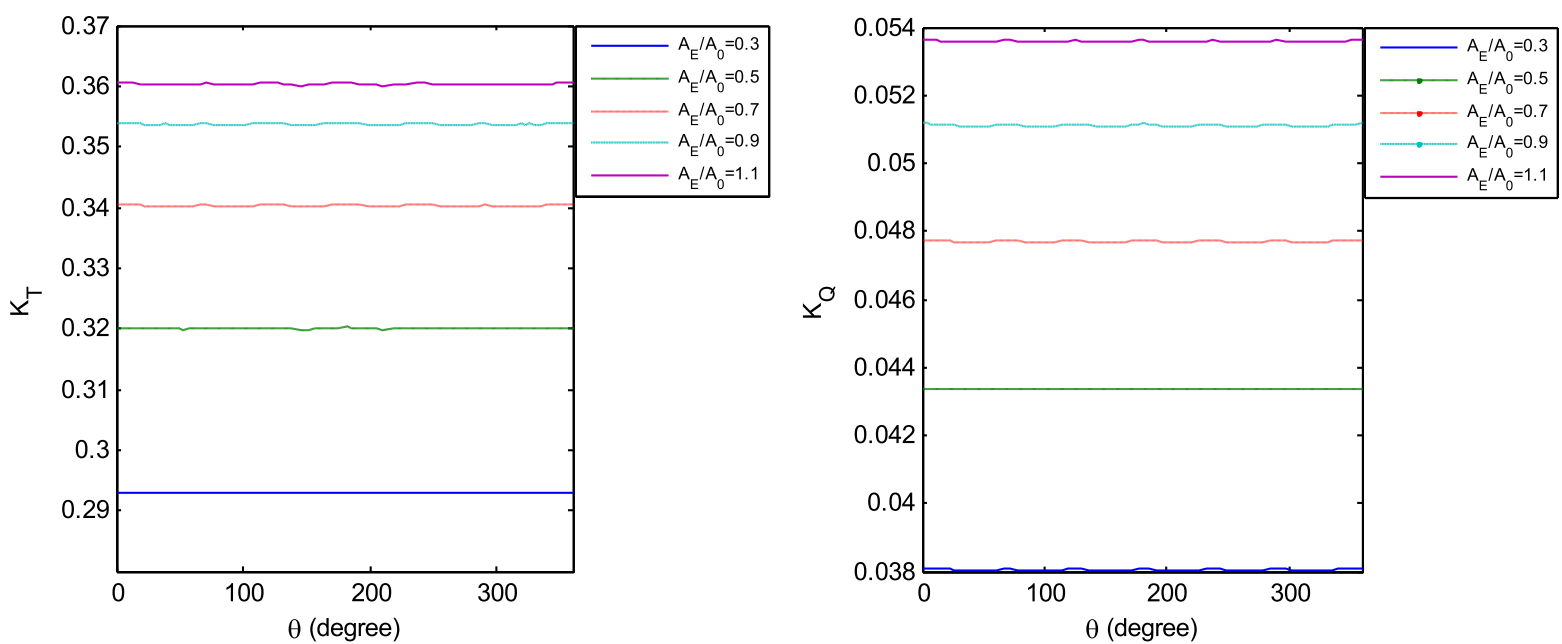

(b) 7000 DWT Tanker

Fig. 10. Total thrust and torque coefficients fluctuations with different expanded area ratio $(Z=6, P / D=0.95)$. 
Table 5. Fourier coefficients of the thrust and torque coefficinet $(Z=6, P / D=0.95, \mathrm{EAR}=0.70)$.

\begin{tabular}{|c|c|c|c|c|c|c|c|c|}
\hline \multirow{3}{*}{$m$} & \multicolumn{4}{|c|}{ Seiun-Maru ship } & \multicolumn{4}{|c|}{7000 DWT Tanker } \\
\hline & \multicolumn{2}{|c|}{ Thrust coefficient $\left(K_{T}\right)$} & \multicolumn{2}{|c|}{ Torque coefficient $\left(K_{Q}\right)$} & \multicolumn{2}{|c|}{ Thrust coefficient $\left(K_{T}\right)$} & \multicolumn{2}{|c|}{ Torque coefficient $\left(K_{Q}\right)$} \\
\hline & $c_{m}$ & $d_{m}$ & $c_{m}^{\prime}$ & $d_{m}^{\prime}$ & $c_{m}$ & $d_{m}$ & $c_{m}^{\prime}$ & $d_{m}^{\prime}$ \\
\hline 0 & $-2.79 \mathrm{E}-07$ & $-9.27 \mathrm{E}-06$ & $-2.65 \mathrm{E}-08$ & $-1.00 \mathrm{E}-06$ & $1.63 \mathrm{E}-05$ & $3.59 \mathrm{E}-07$ & $4.28 \mathrm{E}-06$ & $2.53 \mathrm{E}-07$ \\
\hline 1 & $1.68 \mathrm{E}-05$ & $3.43 \mathrm{E}-06$ & $1.81 \mathrm{E}-06$ & $3.76 \mathrm{E}-07$ & $5.84 \mathrm{E}-05$ & $-1.27 \mathrm{E}-06$ & $6.41 \mathrm{E}-06$ & $-2.57 \mathrm{E}-08$ \\
\hline 2 & $5.40 \mathrm{E}-06$ & $1.28 \mathrm{E}-05$ & $5.67 \mathrm{E}-07$ & $1.42 \mathrm{E}-06$ & $4.16 \mathrm{E}-05$ & $-1.05 \mathrm{E}-05$ & $5.70 \mathrm{E}-06$ & $1.25 \mathrm{E}-07$ \\
\hline 3 & $-2.51 \mathrm{E}-05$ & $4.29 \mathrm{E}-06$ & $-2.73 \mathrm{E}-06$ & $4.46 \mathrm{E}-07$ & $2.78 \mathrm{E}-05$ & $-2.44 \mathrm{E}-06$ & $6.89 \mathrm{E}-06$ & $-3.21 \mathrm{E}-07$ \\
\hline 4 & $-8.27 \mathrm{E}-06$ & $-4.87 \mathrm{E}-05$ & $-8.77 \mathrm{E}-07$ & $-5.26 \mathrm{E}-06$ & $4.14 \mathrm{E}-06$ & $-5.59 \mathrm{E}-06$ & $3.81 \mathrm{E}-06$ & $-6.58 \mathrm{E}-07$ \\
\hline 5 & 0.000531 & -0.00012 & $5.77 \mathrm{E}-05$ & $-1.24 \mathrm{E}-05$ & $4.13 \mathrm{E}-05$ & $-4.65 \mathrm{E}-06$ & $4.72 \mathrm{E}-06$ & $-1.37 \mathrm{E}-07$ \\
\hline 6 & $-1.15 \mathrm{E}-05$ & $-5.35 \mathrm{E}-05$ & $-1.20 \mathrm{E}-06$ & $-5.80 \mathrm{E}-06$ & $-4.56 \mathrm{E}-05$ & $1.86 \mathrm{E}-06$ & $-9.91 \mathrm{E}-06$ & $1.22 \mathrm{E}-06$ \\
\hline 7 & $2.35 \mathrm{E}-05$ & $-1.22 \mathrm{E}-05$ & $2.56 \mathrm{E}-06$ & $-1.30 \mathrm{E}-06$ & $6.96 \mathrm{E}-05$ & $-1.04 \mathrm{E}-05$ & $6.83 \mathrm{E}-06$ & $-1.44 \mathrm{E}-06$ \\
\hline 8 & $6.24 \mathrm{E}-07$ & $2.45 \mathrm{E}-05$ & $9.66 \mathrm{E}-08$ & $2.64 \mathrm{E}-06$ & $8.51 \mathrm{E}-07$ & $3.14 \mathrm{E}-07$ & $2.00 \mathrm{E}-06$ & $-4.89 \mathrm{E}-07$ \\
\hline 9 & $-2.12 \mathrm{E}-05$ & $1.05 \mathrm{E}-06$ & $-2.33 \mathrm{E}-06$ & $1.11 \mathrm{E}-07$ & $-2.42 \mathrm{E}-05$ & $4.43 \mathrm{E}-06$ & $-6.84 \mathrm{E}-10$ & $-2.72 \mathrm{E}-07$ \\
\hline
\end{tabular}

Therefore, the propellers with higher number of blades may help to avoid noise and vibration rather than the propellers with lower number of blades. Table 3 is given the Fourier coefficients of the thrust and torque coefficinets at $Z=5, P /$ $D=0.95, \mathrm{EAR}=0.55$.

Total thrust and torque coefficients fluctuations of propellers with different pitch ratio $(P / D=0.2-1.6)$, fixed number of blades $(Z=4)$, and fixed expanded area ratio $(\mathrm{EAR}=0.55)$ as a function of the blade angular position (0-360 degrees) for one cycle is given in Figure 8. Also, Figure 9 shows total thrust and torque coefficients fluctuations under influence of Seiun-Maru wake of a propeller with $P / D=0.8$. Generally, it can be concluded from Figure 8 that the thrust and torque coefficients decrease with decreasing the pitch ratio for a fixed number of blades and fixed expanded area ratio. Also, it can be conclude from this figure that the fluctuation with respect to the mean thrust and torque coeffiecents at different angular positions almost remain constant with increasing pitch ratio for a fixed number of blades and fixed expanded area ratio under the same operating conditions. Table 4 is given the Fourier coefficients of the thrust and torque coefficinets at $Z=4, P / D=0.80, \mathrm{EAR}=0.55$.

Total thrust and torque coefficients fluctuations of the propeller with different expanded area ratio $(\mathrm{EAR}=0.3-1.1)$, fixed number of blades $(Z=6)$, and fixed pitch ratio $(P / D=0.95)$ as a function of the blade angular position for one cycle is given in Figure 10. In this case similarity with fixed pitch ratio, generally it can be concluded from Figure 10 that the mean of thrust and torque coefficients decrease with decreasing the expanded area ratio for a fixed number of blades and fixed pitch ratio. Also these figures show that the fluctuation with respect to the mean thrust and torque coeffiecents at different angles decrease with decreasing expanded area ratio. Table 5 is given the Fourier coefficients of the thrust and torque coefficinets at $Z=6, P / D=0.95, \mathrm{EAR}=0.70$.
Wake field of a ship strongly depend on the ship hull geometry. A change in wake distribution changes the angle of attack and the cavitation number of the propeller blades. A wide ship creates bigger waves than a thin ship as shown by Noblesse et al. [32]. Wake of the Seiun-Maru hull is something U-shaped hull and generally its fluctuations are bigger than 7000 DWT Tanker with V_shaped hull.

\section{Conclusions}

In this research, the variations of the thrust and torque coefficient fluctuations of the B-series propeller under nonuniform wake behind the Seiun-Maru ship and INSEAN 7000 DWT Tanker hulls were investigated. Also the effects of propeller parameters including number of blades, pitch ratio and expanded area ratio on the thrust and torque coefficients were considered. It can be used the results of this paper for the practical purposes such as propeller predesign with the sufficient accuracy and reliability. The main results of this study are as follows

- the Fourier coefficients of Seiun-Maru ship and INSEAN 7000 DWT Tanker wake fields for the axial and tangential were presented at $0.7 \mathrm{R}$ radial section using DFT interpolation;

- generally the fluctuations of thrust and torque coefficients with the discussed propeller parameters almost were the same;

- the forces of the propeller strongly depend on the expanded area (chord length) and number of blades as well as wake flow. Our engineering approach shows this effect;

- wake of the Seiun-Maru hull is something U-shaped hull and forces fluctuations are bigger than 7000 DWT Tanker with $\mathrm{V}$ shaped hull. Also, each blade is encountered with different velocities at the same time. Due to wake flow, attack angle of the velocity is different at each blade when it is rotating; 
- the mean of thrust and torque coefficients for one blade decreases with increasing the number of blades, while this conclusion is reversed for all blades;

- the fluctuations of thrust and torque coefficients decrease with increasing the number of blades under the same operating conditions;

- the mean of thrust and torque coefficients for one blade and all blades decrease with decreasing the pitch ratio for a fixed number of blades and fixed expanded area ratio. Also, these parameters almost remain constant with increasing pitch ration under the same operating conditions;

- the mean of thrust and torque coefficients for one blade and all blades decrease with decreasing the expanded area ratio for a fixed number of blades and fixed pitch ratio;

- the fluctuation with respect to the mean thrust and torque coeffiecents at different angular positions decrease with decreasing expanded area ratio;

- the presented figures are useful for comparing competitive designs for the same ship and can give a good indication of which will be superior from a loading, vibration, cavitation and noise point of view.

\section{References}

[1] E. Ebert, W. Kröger, N. Damaschke, Hydrodynamic nuclei concentration technique in cavitation research and comparison to phase-doppler measurements, in: Journal of Physics: Conference Series, IOP Publishing, Vol. 656, 2015, p. 012111

[2] S. Kumar, V. Nagarajan, O.P. Sha, Measurement of flow characteristics in propeller slipstream of a twin propeller twin rudder model ship, Int. Shipbuild. Prog. 63 (2017) 1-40

[3] A. Kleinwächter, K. Hellwig-Rieck, H.J. Heinke, N.A. Damaschke, Full-scale total wake field PIV-measurements in comparison with ANSYS CFD calculations: a contribution to a better propeller design process, J. Mar. Sci. Technol. 22 (2017) 388-400

[4] C. Guo, T. Wu, Q. Zhang, W. Luo, Y. Su, Numerical simulation and experimental studies on aft hull local parameterized non-geosim deformation for correcting scale effects of nominal wake field, Brodogradnja 68 (2017) 77-96

[5] H. Ghassemi, The effect of wake flow and skew angle on the ship propeller performance, Sci. Iran. Trans. B: Mech. Eng. 16 (2009) 149-158

[6] B. Ji, X. Luo, Y. Wu, X. Peng, H. Xu, Partially-Averaged Navier-Stokes method with modified $k-\varepsilon$ model for cavitating flow around a marine propeller in a non-uniform wake, Int. J. Heat Mass Transf. 55 (2012) 6582-6588

[7] B. Ji, X. Luo, X. Peng, Y. Wu, H. Xu, Numerical analysis of cavitation evolution and excited pressure fluctuation around a propeller in non-uniform wake. Int. J. Multiph. 43 (2012) 13-21

[8] S. Berger, M. Bauer, M. Druckenbrod, M. Abdel-Maksoud, Investigation of scale effects on propeller-induced pressure fluctuations by a viscous/inviscid coupling approach, in: Proceedings of the Third International Symposium on Marine Propulsors, Tasmania, Australia, 2013

[9] L. Greco, R. Muscari, C. Testa, A. Di Mascio, Marine propellers performance and flow-field prediction by a freewake panel method, J. Hydrodyn. Ser. B 26 (2014) 780-795
[10] K.W. Shin, P.B. Regener, P. Andersen, Methods for cavitation prediction on tip-modified propellers in ship wake fields, in: Fourth International Symposium on Marine Propulsors, 2015 549-555

[11] J.E. Martin, T. Michael, P.M. Carrica, Submarine maneuvers using direct overset simulation of appendages and propeller and coupled CFD/potential flow propeller solver, J. Ship Res. 59 (2015) 31-48

[12] R. Brogliaa, G. Dubbiosoa, D. Durantea, A. DiMascio. Simulation of turning circle by CFD: Analysis of different propeller models and their effect on manoeuvring prediction, Appl. Ocean Res. 39 (2013) 1-10

[13] N. Abbas, N. Kornev, I. Shevchuk, P. Anschau, CFD prediction of unsteady forces on marine propellers caused by the wake nonuniformity and nonstationarity, Ocean Eng. 104 (2015) 659-672

[14] G. Vaz, D. Hally, T. Huuva, N. Bulten, P. Muller, P. Becchi, J.L. Herrer, S. Whitworth, R. Macé, A. Korsström, Cavitating flow calculations for the E779A propeller in open water and behind conditions: code comparison and solution validation, in: Proceedings of the 4 th Int. Symp. on marine Propulsors (SMP'15), Austin, Texas, USA, 2015

[15] F. Alves Pereira, F. Di Felice, F. Salvatore, Propeller Cavitation in non-uniform flow and correlation with the near pressure field, J. Mar. Sci. Eng. 4 (2016) 70

[16] M. Ueno, Y. Tsukada, Estimation of full-scale propeller torque and thrust using free-running model ship in waves, Ocean Eng. 120 (2016) 30-39

[17] S. Sun, L. Li, C. Wang, H. Zhang, Numerical prediction analysis of propeller exciting force for hull-propeller-rudder system in oblique flow. Int. J. Nav. Arch. Ocean Eng. 10 (2017) 69-84

[18] D. Zou, J. Zhang, N. Ta, Z. Rao, The hydroelastic analysis of marine propellers with consideration of the effect of the shaft, Ocean Eng. 131 (2017) 95-106

[19] Y. Ukon, T. Kudo, H. Yuasa, H. Kamiirisa, Measurement of pressure distributions on a full scale propeller-measurement on a highly skewed propeller, J. Soc. Nav. Arch. Jpn. 170 (1991) 111-123

[20] Y. Ukon, T. Kudo, H. Yuasa, H. Kamiirisa, Measurement of pressure distribution on a full scale propellers, in: Sym. of Propeller/Shafting, SNAME, Virginia, 1991

[21] F. Salvatore, F. Di Felice, T. Bugalski, The INSEAN 7000 DWT tanker: results of resistance and propulsion tests, The Italian Marine Technology Re search Institute Rome, Italy, Technical Report CNR-INSEAN/CTO, May 2016 /February 2017

[22] F. Alves Pereira, F. Di Felice, F. Salvatore, Propeller cavitation in non-uniform flow and correlation with the near pressure field, J. Mar. Sci. Eng. 4 (2016)

[23] R. Shamsi, H. Ghassemi, M. Iranmanesh, A Comparison of the BEM and RANS Calculations for the hydrodynamic performance of the PODS, Mech. Ind. 18 (2017)

[24] R. Shamsi, H. Ghassemi, Determining the hydrodynamic loads of the marine propeller forces in oblique flow and offdesign condition, Iran. J. Sci. Technol., Trans. Mech. Eng. 41 (2017) 121-127

[25] M. Motallebi-Nejad, M. Bakhtiari, H. Ghassemi, M. Fadavie, Numerical analysis of ducted propeller and pumpjet propulsion system using periodic computational domain, J. Mar. Sci. Tech. 22 (2017) 559-573 
[26] H. Ghassemi, H. Zakerdoost, Ship hull-propeller system optimization based on the multi-objective evolutionary algorithm, Proc. Inst. Mech. Eng., Part C: J. Mech. Eng. Sci. 231 (2017) 175-192

[27] M. Gorji, H. Ghassemi, J. Mohammadi, Calculation of sound pressure level of marine propelelr in low frequency, J. Low Freq. Noise, Vib. Act. Control 37 (2018) 60-73

[28] M. Chamanara, H. Ghassemi, M. Fadavie, M.A. Ghassemi, Effects of the duct angle and propeller location on the hydrodynamic characteristics of the ducted propeller, Ship Sci. Technol. 11 (2018) 41-48
[29] M. Maghareh, H. Ghassemi, Propeller efficiency enhancement by the blade's tip reformation, Am. J. Mech. Eng. 5 (2017) 70-75

[30] J.S. Carlton, Marine propeller and propulsion, 3rd ed., Elsevier Publication Ltd., 2012

[31] J.P. Ghose, R.P. Gokarn, Basic ship propulsion, Allied Publishers, New Delhi, 2004

[32] F. Noblesse, C. Zhang, J. He, Y. Zhu, C. Yang, W. Li, Observations and computations of narrow Kelvin ship wakes, J. Ocean Eng. Sci. 1 (2016) 52-65

Cite this article as: K. Mahmoodi, H. Ghassemi, H. Nowruzi, Obtaining mathematical functions of the propeller thrust and torque coefficients fluctuations at non-uniform wake flow including geometry effects, Mechanics \& Industry 19, 205 (2018) 